\title{
The key hypoxia regulated gene CAIX is upregulated in basal-like breast tumours and is associated with resistance to chemotherapy
}

\author{
EY Tan', M Yan 2,3, L Campo', C Han ${ }^{4}$, E Takano ${ }^{2,3}$, H Turley', I Candiloro ${ }^{2,3}$, F Pezzella', KC Gatter', \\ EKA Millar ${ }^{5,6}$, SA O'Toole ${ }^{5,7}$, CM McNeil ${ }^{5,8}$, P Crea9, D Segara ${ }^{5,9}$, RL Sutherland ${ }^{5}$, AL Harris ${ }^{4}$ and SB Fox ${ }^{*, 2,3}$ \\ 'Nuffield Department of Clinical Laboratory Sciences, John Radcliffe Hospital, Oxford OX3 9DU, UK; ${ }^{2}$ Pathology, Peter MacCallum Cancer Centre, \\ St Andrews Place, East Melboume 3002, Australia; ${ }^{3}$ Pathology, University of Melbourne, Melboume, Victoria, Australia; ${ }^{4}$ Cancer Research UK Molecular \\ Oncology Laboratory, Weatherall Institute of Molecular Medicine, John Radcliffe Hospital, Oxford OX3 9DU, UK; ${ }^{5}$ Cancer Research Program, Garvan \\ Institute of Medical Research, 384 Victoria Street, Darlinghurst, NSW 2010, Australia; ${ }^{6}$ Department of Anatomical Pathology, South Eastern Area \\ Laboratory Senvice, St George Hospital, Kogarah, NSW 22 17, Australia; ' Department of Pathology (Sydpath), St Vincent's Hospital, Darlinghurst, NSW \\ 2010 , Australia; ${ }^{8}$ Department of Medical Oncology, Westmead Hospital, Sydney, NSW, Australia; ${ }^{9}$ Department of Surgical Oncology, St Vincent's Clinic, \\ Darlinghurst, NSW, Australia
}

\begin{abstract}
Basal-like tumours account for 15\% of invasive breast carcinomas and are associated with a poorer prognosis and resistance to therapy. We hypothesised that this aggressive phenotype is because of an intrinsically elevated hypoxic response. Microarrayed tumours from 188 patients were stained for hypoxia-inducible factor (HIF)- | $\alpha$, prolyl hydroxylase (PHD) I, PHD2, PHD3 and factor inhibiting HIF (FIH)-I, and carbonic anhydrase (CA) IX stained in 456 breast tumours. Tumour subtypes were correlated with standard clincopathological parameters as well as hypoxic markers. Out of 456 tumours 62 (I4\%) tumours were basal-like. These tumours were positively correlated with high tumour grade $(P<0.00 \mathrm{I})$ and were associated with a significantly worse disease-free survival compared with luminal tumours $(P<0.00 \mathrm{I})$. Fifty percent of basal-like tumours expressed $H \mathrm{~F}$ - $\mid \alpha$, and more than half expressed at least one of the PHD enzymes and FIH-I. Basal-like tumours were nine times more likely to be associated with $\mathrm{CAIX}$ expression $(P<0.00 I)$ in a multivariate analysis. Carbonic anhydrase $I X$ expression was positively correlated with tumour size $(P=0.005)$, tumour grade $(P<0.00 \mathrm{I})$ and oestrogen receptor $(E R)$ negativity $(P<0.00 I)$. Patients with any CAIX-positive breast tumour phenotype and in the basal tumour group had a significantly worse prognosis than CAIX-negative tumours when treated with chemotherapy $(P<0.001$ and $P=0.03$, respectively). The association between basal phenotype and CAIX suggests that the more aggressive behaviour of these tumours is partly due to an enhanced hypoxic response. Further, the association with chemoresistance in CAIX-positive breast tumours and basal-like tumours in particular raises the possibility that targeted therapy against HIF pathway or downstream genes such as CAs may be an approach to investigate for these patients.
\end{abstract}

British Journal of Cancer (2009) 100, 405 -4II. doi:I0.1038/sj.bjc.6604844 www.bjcancer.com

(C) 2009 Cancer Research UK

Keywords: breast; hypoxia; carbonic anhydrase; predictive; basal

Current prognostic and predictive markers of invasive breast cancer rely largely on histological indicators such as tumour size, grade, nodal status and receptor status, which define broad patient groups for different treatment regimens. However, it is recognised that there are many patients within such groups who are overtreated or undertreated with conventional therapies, strongly suggesting that current stratification does not fully account for the molecular heterogeneity and diverse biological behaviour of breast cancer. Recently cDNA microarray studies have classified breast cancers broadly into five subtypes, based on their different expression profiles: normal breast-like, luminal A (oestrogen receptor (ER) positive), luminal B (ER positive and proliferative),

\footnotetext{
* Correspondence: Professor SB Fox, Pathology, Peter MacCallum Cancer Centre, St Andrews Place, East Melbourne 3002, Australia; E-mail: stephen.fox@petermac.org

Received 4 September 2008; revised 31 October 2008; accepted II November 2008
}

HER2 overexpressing and basal (Sorlie et al, 2001, 2003), the latter having a particularly poor clinical outcome (Sorlie et al, 2003; Abd El-Rehim et al, 2004; Nielsen et al, 2004).

Basal-like breast cancers derive their name from their characteristic expression of basal and myoepithelial markers such as cytokeratins (CK) 5, 14 and 17 (Jarasch et al, 1988; Wetzels et al, 1991). These tumours account for up to $15 \%$ of all invasive breast cancers (van de Rijn et al, 2002; Abd El-Rehim et al, 2004; Nielsen et al, 2004; Matos et al, 2005). Basal-like tumours are more frequently observed in patients with BRCA1-related cancers (Foulkes et al, 2004). In contrast to the normal breast-like and luminal subtypes, basal-like breast cancers have a particularly aggressive phenotype, being more likely to be high-grade, ER negative (Malzahn et al, 1998; Korsching et al, 2002; Nielsen et al, 2004), and are associated with a higher proliferative index (Korsching et al, 2002; Matos et al, 2005). Expression of basal CKs is also associated with loco-regional recurrence, distant metastasis and a poor overall survival in node-positive and nodenegative patients (Malzahn et al, 1998; van de Rijn et al, 2002). In 
addition, basal-like tumours differ from normal breast-like and luminal tumours in their response to chemotherapy. Although basal-like tumours do not respond well to anthracycline-based therapy (Banerjee et al, 2006), they show an impressive pathological response to paclitaxel followed by a combination of 5-fluorouracil, doxorubicin and cyclophosphamide (Rouzier et al, 2005). They also have a BRCA1 phenotype and therefore are sensitive to platinum-based therapies (Kennedy et al, 2004).

In addition to being mostly high-grade tumours, a so-called triple negative phenotype (ER, progesterone receptor (PR) and HER2 negative), basal-type breast cancers may also have a characteristic central acellular or necrotic zone (Tsuda et al, 1999; Fulford et al, 2006). Tumour necrosis is a consequence of hypoxia. Hypoxia is a predictor of poor disease-free and overall survival in breast cancer (Fisher et al, 1993; Hockel and Vaupel, 2001), and is associated with resistance to radiation and certain chemotherapeutic regimes (Teicher et al, 1990). As the hypoxiainducible factor (HIF) pathway has been shown to be pivotal in the hypoxic tumour response and to mediate many of the above adverse effects, and in view of the link between basal-like breast cancer, hypoxia and an aggressive phenotype, we have examined the HIF pathway, including the expression of HIF- $1 \alpha$, its regulatory enzymes the prolyl hydroxylase domain enzymes PHD-1, PHD-2, PHD-3, factor inhibiting HIF-1 (FIH-1) and carbonic anhydrase (CA) IX, a downstream target of HIF- $1 \alpha$ in a series of breast cancers, and compared the expression of each marker by correlating it with various standard clinicopathological parameters.

\section{MATERIALS AND METHODS}

\section{Patient characteristics}

Tumour tissue microarray cores ( $1 \mathrm{~mm}$ cores) were collected from 621 invasive breast carcinomas collected from patients who had undergone surgery at the John Radcliffe Hospital, Oxford, UK and from the Garvan Institute, Sydney, Australia. This study has Ethical Committee approvals (number JR C02.216 and HREC SVH H94/080, HREC SVH 06336 H00036). All patients had operable breast carcinomas and were not diagnosed with metastatic disease at the time of presentation. Information regarding patient characteristics, including age, tumour size, grade, histology, nodal status, ER and HER2 status, were collected from the clinical and pathological records. The median age of patients included in this study was 55 years (range 24-87 years). Eighty-eight percent of tumours were invasive ductal of no specific type, $3 \%$ were invasive lobular carcinoma and 3\% were of other histological classifications (data was unavailable for the remaining 6\%). Median tumour size was $20 \mathrm{~mm}$ and the median tumour grade was two. Forty-four percent of patients had nodal disease. Sixty-eight percent of tumours were ER positive and $16 \%$ were HER2 positive. Patients less than 50 years of age with node-positive, ER-negative tumours or tumours larger than $3 \mathrm{~cm}$ received adjuvant chemotherapy (cyclophosphamide, methotrexate and 5-fluorouracil (CMF) or adriamycin and cyclophosphamide (AC). Patients with hormoneresponsive tumours who were more than 50 years of age received 5 years of endocrine therapy. Patients were followed up for a median period of 131.9 months. During this time, 137 patients developed recurrence $(30.0 \%)$ and 99 deaths $(21.7 \%)$ were considered as breast-cancer related.

\section{Immunohistochemistry}

Formalin-fixed paraffin-embedded tissue sections were stained for the various hypoxic markers (Supplementary Table 1). Substitution of the primary antibody with phosphate-buffered saline served as a negative control. Transfected COS-1 cells expressing
PHD1, PHD2, PHD3, FIH-1 and HIF-1 $\alpha$ were used as positive controls. In each run a tumour is known to be positive for CAIX was included.

Scoring was carried out by two observers simultaneously. ER, HER2, EGFR and CK5/6 staining was used to classify tumours into four subgroups as per Neilson et al. basal group (ER negative, HER2 negative, CK5/6 and/or EGFR positive), luminal group (ER positive, HER2 negative), HER2 group (HER2 positive) and a negative group (ER negative, HER2 negative, CK5/6 negative and EGFR negative) (Nielsen et al, 2004). Tumours with any nuclear staining for HIF- $1 \alpha$ were considered positive in the analysis. The levels of staining for PHD1, PHD2 and PHD3 were scored with respect to the percentage of cells and the intensity of staining in the cytoplasm. The scoring system for intensity was: $0=$ no staining, $1=$ weak staining, $2=$ moderate staining, $3=$ strong staining; and the scoring system for percentage was: $0=$ no cells staining positive, $1=\leqslant 10 \%$ cells staining positive, $2=11-50 \%$ positive cells, $3=51-80 \%$ positive cells, $4=\geqslant 80 \%$ positive cells. Tumours with a cytoplasmic intensity score of $\geqslant 2$ and a percentage score of $\geqslant 1$ were considered positive for PHD1, PHD2 and PHD3 in the analysis, in accordance with their site of action. Only tumours showing a strong membranous staining in $\geqslant 10 \%$ or more cells were considered positive for CAIX (Tan et al, 2007). Tumours with a nuclear intensity score of $\geqslant 2$ and a percentage score of $\geqslant 1$ were considered positive for FIH-1 in the analysis (Tan et al, 2007). Owing to loss of tumour cores, only 456 out of 621 patients with full phenotype of ER, HER2, EGFR and CK5/6, which are required to classify tumours were available. Similarly, HIF- $1 \alpha$ and the PHDs were available in only 188 out of 456 tumours.

\section{Statistical methods}

Correlations were evaluated using either the one-way ANOVA or $\chi^{2}$ test where appropriate. Kaplan-Meier survival curves were calculated using tumour recurrence (defined as the first reappearance of tumour at any site after definitive treatment) and cancer-related death as the endpoints and compared using a logrank test. Binary logistic regression was used for multivariate analyses and the Cox proportional hazard regression model was used to identify independent prognostic factors for disease-free and overall survival. The analyses were carried out with SPSS 16.0 (SPSS Inc., 233 South Wacker Drive, IL, USA). A two-tailed $P$-value test was used in all analyses and a $P$-value of $<0.05$ was considered statistically significant.

\section{RESULTS}

\section{Expression of ER, HER2, CK5/6 and EGFR in invasive breast cancer}

Out of 456 tumours 310 (68\%) were ER positive; of these, 289 tumours were also HER2 negative and were therefore considered to be of the luminal group (Table 1). Seventy-five tumours (16\%) were HER2 positive, regardless of their ER, CK5/6 and EGFR status, and were considered to be of the HER2 group. Of the 169 ER-negative tumours, $62(14 \%)$ were also HER2 negative but CK5/6 and/or EGFR positive; these were considered to be of the basal-like group. Thirty tumours were negative for ER, HER2, CK5/ 6 and EGFR and were considered to be of the negative group (Table 1) (Supplementary material Figure 1).

\section{Expression of HIF-1 $\alpha$ and its regulatory enzymes PHD1, PHD2, PHD3 and FIH}

Ninety-four out of 188 tumours (50\%) stained positive for HIF-1 $\alpha$ (Table 1) (Supplementary material Figure 1). Of these, 64 tumours 
Table I Correlation analysis of 456 invasive breast carcinomas with clinicopathological parameters and CA9

\begin{tabular}{|c|c|c|c|c|c|}
\hline & $\begin{array}{l}\text { Luminal } \\
(n=289)\end{array}$ & $\begin{array}{c}\text { HER2 } \\
(n=75)\end{array}$ & $\begin{array}{c}\text { Basal } \\
(n=62)\end{array}$ & $\begin{array}{c}\text { Negative } \\
(n=30)\end{array}$ & $P$-value \\
\hline Patient age & & & & & 0.64 \\
\hline Median (years) & 56.0 & 55.2 & 54.0 & 52.7 & \\
\hline Tumour size & & & & & 0.40 \\
\hline Median (mm) & 18.0 & 22.0 & 22.5 & 20.5 & \\
\hline Tumour grade & & & & & $<0.001$ \\
\hline I & 71 & 4 & 2 & 4 & \\
\hline 2 & 156 & 16 & 12 & 12 & \\
\hline 3 & 58 & 54 & 47 & 14 & \\
\hline Nodal status & & & & & 0.75 \\
\hline Negative & 162 & 40 & 34 & 17 & \\
\hline Positive & 125 & 34 & 28 & 13 & \\
\hline CAIX & & & & & $<0.001$ \\
\hline Negative & 242 & 27 & 57 & 22 & \\
\hline Positive & 14 & 26 & 16 & 3 & \\
\hline Nuclear HIFI $\alpha$ & & & & & 0.53 \\
\hline Negative & 54 & 10 & 13 & । & \\
\hline Positive & 64 & 12 & 13 & 5 & \\
\hline Cytoplasmic PHD I & & & & & 0.76 \\
\hline Negative & 68 & 10 & 15 & 3 & \\
\hline Positive & 51 & 12 & 11 & 3 & \\
\hline Cytoplasmic PHD2 & & & & & 0.41 \\
\hline Negative & 71 & 9 & 16 & 4 & \\
\hline Positive & 47 & 11 & 7 & 2 & \\
\hline Cytoplasmic PHD3 & & & & & 0.87 \\
\hline Negative & 70 & 13 & 14 & 3 & \\
\hline Positive & 43 & 10 & 11 & 3 & \\
\hline Nuclear FIH-I & & & & & 0.51 \\
\hline Negative & 45 & 6 & 12 & 3 & \\
\hline Positive & 80 & 17 & 15 & 3 & \\
\hline
\end{tabular}

CAIX = carbonic anhydrase IX; PHD = prolyl hydroxylase. $n<456$ because data are not available.

(68\%) were of the luminal group, 13 tumours (14\%) were of the basal group, $12(13 \%)$ were of the HER2 group and 5 (5\%) were of the negative group. Although only 8,10 and $12 \%$ of luminal, basal-like and HER2 tumours, respectively, expressed all three PHD enzymes, the majority expressed at least one PHD enzyme (63, 52 and 72 , respectively) (Table 1). None of the six negative tumours expressed all three PHD enzymes although all expressed at least one PHD enzyme. More than half of all the tumours expressed FIH-1 (63\% of luminal tumours, $52 \%$ of basal tumours, $68 \%$ of HER2 tumours and $50 \%$ of negative tumours) (Table 1).

\section{Correlation of CAIX expression in invasive breast carcinoma with clinicopathological parameters}

CAIX was positive in 59 out of 407 tumours (14\%) (Table 2). The majority of these tumours (26 out of $59(44 \%)$ ) were of the basallike group. Carbonic anhydrase IX expression was significantly correlated with a larger tumour size $(P=0.005)$, high tumour grade $(P<0.001)$ and ER negativity $(P<0.001)$ (Table 2$)$. There was no correlation with patient age, nodal status or HER2 status $(P>0.05)$ (Table 2). CAIX expression showed no significant correlation with HIF- $1 \alpha$ expression (Table 2 ).
Table 2 Correlation analysis of CAIX expression and clinicopathological parameters

\begin{tabular}{|c|c|c|c|}
\hline & $\begin{array}{l}\text { CAIX positive } \\
(n=59)\end{array}$ & $\begin{array}{l}\text { CAIX negative } \\
(n=348)\end{array}$ & $P$-value \\
\hline Patient age & & & 0.96 \\
\hline Median (years) & 55.0 & 57.0 & \\
\hline Tumour size & & & 0.005 \\
\hline Median (mm) & 25.0 & 19.0 & \\
\hline Tumour grade & & & $<0.001$ \\
\hline 1 & 0 & 96 & \\
\hline 2 & 19 & 189 & \\
\hline 3 & 56 & 154 & \\
\hline Nodal status & & & 0.168 \\
\hline Negative & 34 & 242 & \\
\hline Positive & 40 & 195 & \\
\hline ER status & & & $<0.001$ \\
\hline Negative & 54 & 110 & \\
\hline Positive & 19 & 326 & \\
\hline HER2 status & & & 0.065 \\
\hline Negative & 43 & 291 & \\
\hline Positive & 16 & 57 & \\
\hline Nuclear HIF-I $\alpha$ & & & 0.13 \\
\hline Negative & 6 & 54 & \\
\hline Positive & 15 & 62 & \\
\hline
\end{tabular}

Table 3 Multivariate analysis binary logistic regression model of the effect of CAIX expression on tumour subtype, using luminal tumours as a baseline $(n=406)$

\begin{tabular}{lccc}
\hline & Odds ratio & $\mathbf{9 5 \%} \mathbf{C l}$ & P-value \\
\hline Tumour size & 1.00 & $0.98-1.03$ & 0.79 \\
Grade & 2.7 & $1.45-5.00$ & 0.002 \\
Basal tumours & 8.9 & $3.86-20.29$ & $<0.001$ \\
HER2 tumours & 2.7 & $1.16-6.21$ & 0.02 \\
Negative tumours & 1.6 & $0.40-6.09$ & 0.52 \\
\hline
\end{tabular}

CAIX = carbonic anhydrase IX.

\section{Correlation of breast tumours stratified by intrinsic} subtype with CAIX, HIF-1 $\alpha$ and its regulatory enzymes

Basal-like tumours were 8.9 times more likely to express CAIX $(P<0.001,95 \%$ CI 3.86-20.29) than luminal tumours (Table 3$)$. This association is significant $(<0.001)$ even after controlling for the effect of tumour size and grade. There was no significant correlation between breast tumour subtypes and HIF- $1 \alpha$ or its regulatory enzymes $(P>0.05)$.

\section{Correlation of breast tumours stratified by intrinsic subtype with clinicopathological parameters and survival outcome}

Basal-like tumours were associated with high tumour grade $(P<0.001)$, but were not correlated with patient age, tumour size or nodal status $(P>0.05)$. Basal-like tumours and HER2 tumours shared a similar poor disease-free survival outcome (Supplementary Figure 2) and were associated with a significantly shorter disease-free survival compared with luminal tumours $(P<0.001$, 
OR 2.58, 95\% CI 1.82-3.65) (Negative tumours were excluded from the analysis because of the small sample size but are included the figure).

\section{CAIX expression and survival in breast cancer patients}

Patients with tumours expressing CAIX had a significantly worse disease-free survival $(P<0.001)$ (Figure 1A). There was a significant difference in survival in patients with any type of breast carcinoma treated with chemotherapy stratified by CAIX $(P<0.001)$ (Figure 1B). Patients with CAIX-positive basal-like breast cancers who were treated with chemotherapy had a significantly shorter overall survival $(P=0.03)$ than treated patients with CAIX-negative basal-like breast cancers (Figure 1C). In the absence of chemotherapy treatment, there was no significant difference in overall survival among the intrinsic subtypes $(P=0.07)$, or when basal-like carcinomas were stratified according to CAIX expression $(P=0.27)$. There was no significant difference in overall survival in patients not treated with chemotherapy with any type of breast carcinoma $(P=0.07)$ or basal-like carcinoma stratified by CAIX $(P=0.27)$. In a multivariate Cox regression model patients who had tumours that were CAIX positive and who were treated with chemotherapy had a significantly shorter overall survival $(P<0.001)$, whereas CAIX had no effect on survival in patients not treated with chemotherapy $(P=0.48)$ (Table $4 \mathrm{~A}$ and $\mathrm{B})$. To test for treatment interactions, CAIX, chemotherapy and their interaction variables were entered into the Cox regression model as a second block. The interaction of chemotherapy with CAIX was significant in the final model $(P=0.04)$ (Table 4C).

\section{DISCUSSION}

mRNA expression profile studies have confirmed the longstanding histological observation that breast cancer is a heterogeneous disease (Perou et al, 2000; Sorlie et al, 2001, 2003). These studies have broadly classified breast cancers into four categories: luminal A (strongly ER positive), luminal B (also ER positive but proliferative), HER2 and basal-like groups. Although these categories were identified using unsupervised clustering, the groupings also conferred prognostic information, with carcinomas of the basal-like group having a shorter survival than tumours of the luminal group (Sorlie et al, 2001) and being resistant to anthracycline-based chemotherapy (Banerjee et al, 2006). Expression of the hypoxia-inducible factor- $1 \alpha$ is also associated with a poor prognosis and resistance to chemotherapy (Teicher et al, 1981; Schindl et al, 2002; Bos et al, 2003), and in view of the association between basal-like breast cancer, necrosis, their aggressive behaviour and poor response to chemotherapy we hypothesised that these tumours may have an intrinsically enhanced hypoxic response. We therefore examined the hypoxic pathway in a series of breast cancers.

Although there is no generally recognised definition of the categories for stratification into intrinsic subgroups (different studies using various markers such as CK5, CK14, CK17, EGFR, KIT, p63 and smooth muscle actin (Nagle et al, 1986; Wetzels et al, 1991; Malzahn et al, 1998; Tsuda et al, 1999; van de Rijn et al, 2002; Abd El-Rehim et al, 2004; Matos et al, 2005; Fulford et al, 2006) to identify basal-like tumours), in this study we have used the classification developed by Nielsen et al (2004). This uses a combination of ER, HER2, CK5 and EGFR to generate four groups, which in this study gives a frequency of basal-like cancers in this
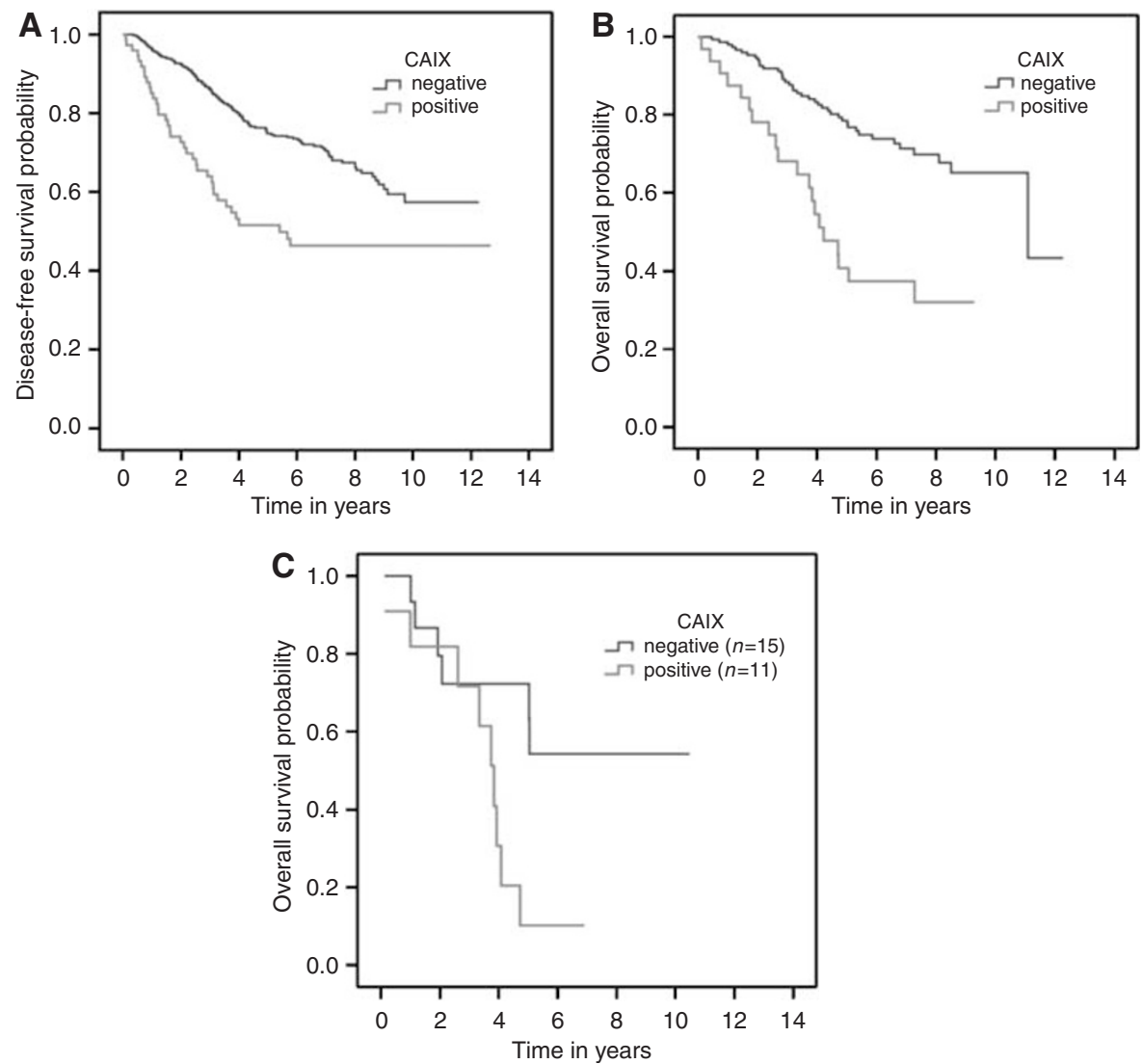

Figure I (A) Kaplan-Meier disease-free survival curves stratifying patients by CAIX expression $(P<0.00 \mathrm{I})(n=407)$. (B) Kaplan-Meier overall survival curves stratifying all tumours treated with chemotherapy by expression of CAIX $(P<0.00 I)(n=427)$. (C) Kaplan-Meier overall survival curves stratifying patients with basal-like tumours treated with chemotherapy by expression of CAIX $(P=0.03)(n=26)$. 
Table 4A Cox regression model, overall survival, all breast cancers treated with chemotherapy $(n=\mid 82)$

\begin{tabular}{lccc}
\hline & Odds ratio & $\mathbf{9 5 \%} \mathbf{~ C l}$ & P-value \\
\hline Nodal status & 1.77 & $0.62-5.05$ & 0.29 \\
Grade & 2.38 & $1.36-4.164$ & 0.002 \\
CAIX & 3.20 & $1.79-5.701$ & $<0.001$ \\
Size & 1.04 & $1.02-1.058$ & $<0.001$ \\
\hline
\end{tabular}

CAIX = carbonic anhydrase IX

Table 4B Cox regression model, overall survival, all breast cancers treated with chemotherapy $(n=262)$

\begin{tabular}{lccr}
\hline & Odds ratio & $\mathbf{9 5 \%} \mathbf{C l}$ & $\boldsymbol{P}$-value \\
\hline Nodal status & 2.27 & $1.04-4.96$ & 0.04 \\
Grade & 1.90 & $1.12-3.25$ & 0.02 \\
CAIX & 1.33 & $0.60-2.95$ & 0.48 \\
Size & 1.04 & $1.02-1.06$ & $<0.001$ \\
\hline
\end{tabular}

CAIX = carbonic anhydrase IX

Table 4C Cox regression model, overall survival, all breast cancers with CAIX and chemotherapy as interaction variables $(n=44 \mathrm{I})$

\begin{tabular}{lccc}
\hline & Odds ratio & $\mathbf{9 5 \%} \mathbf{C l}$ & P-value \\
\hline Grade & 1.98 & $1.34-2.92$ & 0.001 \\
Age & 1.00 & $0.99-1.02$ & 0.65 \\
Size & 1.04 & $1.03-1.05$ & $<0.001$ \\
Oestrogen receptor & 0.74 & $0.46-1.20$ & 0.22 \\
Nodal status & 2.22 & $1.15-4.26$ & 0.02 \\
& & & \\
Additions to model & 1.09 & $0.49-2.42$ & 0.83 \\
$\quad$ CAIX & 0.75 & $0.38-1.49$ & 0.41 \\
Chemotherapy & 2.65 & $1.03-6.82$ & 0.04 \\
CAIX $\times$ chemotherapy & & & \\
\hline
\end{tabular}

CAIX = carbonic anhydrase $I X$.

cohort similar to that described earlier (van de Rijn et al, 2002; Abd El-Rehim et al, 2004; Nielsen et al, 2004; Matos et al, 2005).

Central to the hypoxic response is the transcription factor HIF. We have examined the role of the key pathway members regulating HIF-mediated transcription, including HIF- $1 \alpha$, the PHDs, FIH and CAIX in a series of breast cancers classified into intrinsic subtypes as described above (Wykoff et al, 2000). We observed that basallike tumours were many times more likely to express CAIX. Carbonic anhydrase IX is a transmembrane protein involved in maintaining a low pericellular $\mathrm{pH}$ through its reversible conversion of carbon dioxide and water into carbonic acid (Pastorek et al, 1994; Opavsky et al, 1996), and has been shown to maintain survival of breast tumour cells under hypoxic conditions (Potter and Harris, 2003). Carbonic anhydrase IX is not present in normal breast tissues (Bartosova et al, 2002), but is upregulated in invasive tumours with increasing intensity, with increasing distance from tumour vessels (Span et al, 2003) tightly under the regulation of HIF-1 $\alpha$ (Grabmaier et al, 2004). Carbonic anhydrase IX expression has been shown to correlate with the distribution of pimonidazole, a chemical marker of hypoxia (Opavsky et al, 1996; Wykoff et al, 2000) and with hypoxia measured by Eppendorf microelectrode in advanced cervical cancer (Loncaster et al, 2001). On the basis of these data it has been suggested that CAIX immunohistochemistry is a surrogate marker for detecting hypoxia in tumour samples. Thus, the association between basal phenotype and CAIX supports the notion that these tumours have an enhanced hypoxic response (Wykoff et al, 2000; Lal et al, 2001).
Nevertheless, despite a strong correlation with CAIX, we did not observe a correlation between basal tumours and HIF- $1 \alpha$ or between CAIX and HIF- $1 \alpha$ in this study. This is unlikely to be due to spatial reasons because TMA are ideal for investigating relationships between biomarkers as the same area of tumour is being examined, but is probably due to the difference in half-lives of HIF- $1 \alpha$ and CAIX. Hypoxia-inducible factor $-1 \alpha$ is rapidly degraded within minutes of reoxygenation (Jiang et al, 1996), whereas CAIX has a half-life of 2-3 days (Turner et al, 2002; Rafajova et al, 2004). This absence of an association is in agreement with reports (Tomes et al, 2003; Sobhanifar et al, $2005)$ of the presence of CAIX without HIF- $1 \alpha$ expression in perinecrotic regions in solid tumours (Sobhanifar et al, 2005).

CAIX expression, like a basal-like phenotype, is associated with an increased risk of recurrence and poorer overall survival (Chia et al, 2001). In this series, those patients with tumours of either a basallike phenotype or expressing CAIX were associated with an adverse outcome. Nevertheless, in this study and in others reported earlier, CAIX expression is also positively correlated with high tumour grade and size (Chia et al, 2001; Span et al, 2003), the former feature also characteristic of basal tumours. Thus, hypoxic stress may not be part of the basal intrinsic subtype but might be due to an association with grade. Although this cannot be completely discounted, our data show that both basal-like and HER2 cancers are significantly associated with high tumour grade (as expected) but the basal group was more likely to be CAIX positive, whereas the HER2 subtype was less likely to be CAIX positive. Furthermore, in a multivariate analysis including tumour size and grade, basal-like phenotype was still associated with CAIX expression. Thus, the data are strongly suggestive of an enhanced hypoxic drive in this tumour type. This is further supported by interrogation of expression data sets (Oncomine, www.oncomine.org), where there is significant upregulation of not only HIF- $1 \alpha$ and CAIX but also other HIF- $1 \alpha$-regulated genes such as vascular endothelial growth factor-A, BNIP3 and Glut-1. Moreover, patients with basal-like tumours who have not received chemotherapy have a similar prognosis irrespective of CAIX expression, whereas patients with basal-like tumours that are CAIX positive and who have received chemotherapy have a significantly shorter overall survival than patients with basal-like tumours that are CAIX negative. This suggests that CAIX-positive basal-like tumours are particularly resistant to chemotherapy, in contrast to CAIXnegative basal-like tumours, which are able to respond to chemotherapy. A potential mechanism for this action is through trapping of chemotherapeutic agents outside the cell when the extracellular environment is acidic (Mahoney et al, 2003).

The resistance effect of CAIX/hypoxia seems to hold irrespective of tumour subtype as, unlike patients not treated with chemotherapy, treated patients with any tumour phenotype positive for CAIX also had a significantly worse survival than patients with tumours negative for CAIX in the multivariate analyses. This is in keeping with our studies in the neoadjuvant context, in which CAIX was associated with a shorter relapse-free survival in patients treated with CMF (Generali et al, 2006a, b), and in patients treated in the adjuvant setting, in which CAIX measured by RT - PCR was associated with chemoresistance (Span et al, 2003). Thus, these data suggest that CAIX is predictive rather than prognostic.

Molecular genetic studies of basal-like breast carcinomas have shown that tumours with a basal-like phenotype have a higher number of unbalanced chromosomal changes and rate of loss of heterozygosity than luminal-type breast tumours (Korsching et al, 2002; Jones et al, 2004). In addition, basal-like tumours are a distinctive feature of BRCA1-associated breast cancers. Although BRCA1 is involved in a large number of cellular processes, it is the maintenance of genomic stability that has been proposed to be the principal factor underlying cancer predisposition in mutation carriers (Baldeyron et al, 2002). Thus, it is also of interest that hypoxia is recognised to induce genomic instability (Cheng and Loeb, 1993; Sutherland, 1998; Semenza, 2000; Chan et al, 2008), 
and it is interesting to speculate whether the genomic alterations observed in basal-like breast carcinomas may partly be the result of the enhanced hypoxic response in this subtype. Nevertheless, these genomic studies have been carried out on a small number of tumours (Jones et al, 2001, 2004) and additional data are required to support this thesis.

In summary, the more aggressive phenotype seen in basal-like tumours may be at least partly due to the intrinsically enhanced hypoxic properties of basal-like breast cancers. It suggests that as this tumour type is particularly difficult to treat, because they are both hormonal non-responsive and resistant to chemotherapy, targeting HIF with small molecule inhibitors, HRE-regulated gene therapies, carbonic anhydrase inhibitors or the use of bio-reductive drugs may be of particular use in treating this aggressive cancer (Supuran, 2008).

\section{ACKNOWLEDGEMENTS}

This study has been supported by the National Medical Research Council (NMRC), Singapore, the Victorian Breast Cancer Research Consortium, Australia, the Victorian Cancer Biobank, the European Union 6th Framework Euroxy, NHS Biomedical Research Centre Oxford, Cancer Research UK, the National Health and Medical Research Council of Australia (NHMRC), the Cancer Institute NSW, the RT Hall Trust and the Petre Foundation. We would also like to thank Dr Kingsley Micklem for help with the photomicrographs.

Supplementary Information accompanies the paper on British Journal of Cancer website (http://www.nature.com/bjc)

\section{REFERENCES}

Abd El-Rehim DM, Pinder SE, Paish CE, Bell J, Blamey RW, Robertson JF, Nicholson RI, Ellis IO (2004) Expression of luminal and basal cytokeratins in human breast carcinoma. J Pathol 203: 661-671

Baldeyron C, Jacquemin E, Smith J, Jacquemont C, De Oliveira I, Gad S, Feunteun J, Stoppa-Lyonnet D, Papadopoulo D (2002) A single mutated BRCA1 allele leads to impaired fidelity of double strand break endjoining. Oncogene 21: $1401-1410$

Banerjee S, Reis-Filho JS, Ashley S, Steele D, Ashworth A, Lakhani SR, Smith IE (2006) Basal-like breast carcinomas: clinical outcome and response to chemotherapy. J Clin Pathol 59: 729-735

Bartosova M, Parkkila S, Pohlodek K, Karttunen TJ, Galbavy S, Mucha V, Harris AL, Pastorek J, Pastorekova S (2002) Expression of carbonic anhydrase IX in breast is associated with malignant tissues and is related to overexpression of c-erbB2. J Pathol 197: 314-321

Bos R, van der Groep P, Greijer AE, Shvarts A, Meijer S, Pinedo HM, Semenza GL, van Diest PJ, van der Wall E (2003) Levels of hypoxiainducible factor-1alpha independently predict prognosis in patients with lymph node negative breast carcinoma. Cancer 97: 1573-1581

Chan N, Koritzinsky M, Zhao H, Bindra R, Glazer PM, Powell S, Belmaaza A, Wouters B, Bristow RG (2008) Chronic hypoxia decreases synthesis of homologous recombination proteins to offset chemoresistance and radioresistance. Cancer Res 68: 605-614

Cheng KC, Loeb LA (1993) Genomic instability and tumor progression: mechanistic considerations. Adv Cancer Res 60: 121-156

Chia SK, Wykoff CC, Watson PH, Han C, Leek RD, Pastorek J, Gatter KC, Ratcliffe P, Harris AL (2001) Prognostic significance of a novel hypoxiaregulated marker, carbonic anhydrase IX, in invasive breast carcinoma. J Clin Oncol 19: 3660-3668

Fisher ER, Anderson S, Redmond C, Fisher B (1993) Pathologic findings from the National Surgical Adjuvant Breast Project protocol B-06. 10-year pathologic and clinical prognostic discriminants. Cancer 71: $2507-2514$

Foulkes WD, Brunet JS, Stefansson IM, Straume O, Chappuis PO, Begin LR, Hamel N, Goffin JR, Wong N, Trudel M, Kapusta L, Porter P, Akslen LA (2004) The prognostic implication of the basal-like (cyclin E high/p27 low/p53+/glomeruloid-microvascular-proliferation+) phenotype of BRCA1-related breast cancer. Cancer Res 64: 830-835

Fulford LG, Easton DF, Reis-Filho JS, Sofronis A, Gillett CE, Lakhani SR, Hanby A (2006) Specific morphological features predictive for the basa phenotype in grade 3 invasive ductal carcinoma of breast. Histopathology 49: $22-34$

Generali D, Berruti A, Brizzi MP, Campo L, Bonardi S, Wigfield S, Bersiga A, Allevi G, Milani M, Aguggini S, Gandolfi V, Dogliotti L, Bottini A, Harris AL, Fox SB (2006a) Hypoxia-inducible factor-1 \{alpha\} expression predicts a poor response to primary chemoendocrine therapy and disease-free survival in primary human breast cancer. Clin Cancer Res 12: $4562-4568$

Generali D, Fox SB, Berruti A, Brizzi MP, Campo L, Bonardi S, Wigfield SM, Bruzzi P, Bersiga A, Allevi G, Milani M, Aguggini S, Dogliotti L, Bottini A, Harris AL (2006b) Role of carbonic anhydrase IX expression in prediction of the efficacy and outcome of primary epirubicin/tamoxifen therapy for breast cancer. Endocr Relat Cancer 13: 921 - 930
Grabmaier K, MC AdW, Verhaegh GW, Schalken JA, Oosterwijk E (2004) Strict regulation of CAIX(G250/MN) by HIF-1alpha in clear cell renal cell carcinoma. Oncogene 23: 5624-5631

Hockel M, Vaupel P (2001) Tumor hypoxia: definitions and current clinical, biologic, and molecular aspects. J Natl Cancer Inst 93: 266-276

Jarasch ED, Nagle RB, Kaufmann M, Maurer C, Bocker WJ (1988) Differential diagnosis of benign epithelial proliferations and carcinomas of the breast using antibodies to cytokeratins. Hum Pathol 19: 276-289

Jiang BH, Semenza GL, Bauer C, Marti HH (1996) Hypoxia-inducible factor 1 levels vary exponentially over a physiologically relevant range of $\mathrm{O} 2$ tension. Am J Physiol 271: C1172 - C1180

Jones C, Ford E, Gillett C, Ryder K, Merrett S, Reis-Filho JS, Fulford LG, Hanby A, Lakhani SR (2004) Molecular cytogenetic identification of subgroups of grade III invasive ductal breast carcinomas with different clinical outcomes. Clin Cancer Res 10: 5988-5997

Jones C, Nonni AV, Fulford L, Merrett S, Chaggar R, Eusebi V, Lakhani SR (2001) CGH analysis of ductal carcinoma of the breast with basaloid/ myoepithelial cell differentiation. Br J Cancer 85: 422-427

Kennedy R, Quinn J, Mullan P, Johnston P, Harkin D (2004) The role of BRCA1 in the cellular response to chemotherapy. J Natl Cancer Inst 96: $1659-1668$

Korsching E, Packeisen J, Agelopoulos K, Eisenacher M, Voss R, Isola J, van Diest PJ, Brandt B, Boecker W, Buerger H (2002) Cytogenetic alterations and cytokeratin expression patterns in breast cancer: integrating a new model of breast differentiation into cytogenetic pathways of breast carcinogenesis. Lab Invest 82: 1525-1533

Lal A, Peters H, St Croix B, Haroon ZA, Dewhirst MW, Strausberg RL, Kaanders JH, van der Kogel AJ, Riggins GJ (2001) Transcriptional response to hypoxia in human tumors. J Natl Cancer Inst 93: 1337-1343

Loncaster JA, Harris AL, Davidson SE, Logue JP, Hunter RD, Wycoff CC, Pastorek J, Ratcliffe PJ, Stratford IJ, West CM (2001) Carbonic anhydrase (CA IX) expression, a potential new intrinsic marker of hypoxia: correlations with tumor oxygen measurements and prognosis in locally advanced carcinoma of the cervix. Cancer Res 61: 6394-6399

Mahoney BP, Raghunand N, Baggett B, Gillies RJ (2003) Tumor acidity, ion trapping and chemotherapeutics. I. Acid $\mathrm{pH}$ affects the distribution of chemotherapeutic agents in vitro. Biochem Pharmacol 66: 1207-1218

Malzahn K, Mitze M, Thoenes M, Moll R (1998) Biological and prognostic significance of stratified epithelial cytokeratins in infiltrating ductal breast carcinomas. Virchows Arch 433: 119-129

Matos I, Dufloth R, Alvarenga M, Zeferino LC, Schmitt F (2005) p63, cytokeratin 5, and P-cadherin: three molecular markers to distinguish basal phenotype in breast carcinomas. Virchows Arch 447: 688-694

Nagle RB, Bocker W, Davis JR, Heid HW, Kaufmann M, Lucas DO, Jarasch ED (1986) Characterization of breast carcinomas by two monoclonal antibodies distinguishing myoepithelial from luminal epithelial cells. J Histochem Cytochem 34: 869-881

Nielsen TO, Hsu FD, Jensen K, Cheang M, Karaca G, Hu Z, Hernandez-Boussard T, Livasy C, Cowan D, Dressler L, Akslen LA, Ragaz J, Gown AM, Gilks CB, van de Rijn M, Perou CM (2004) Immunohistochemical and clinical characterization of the basal-like subtype of invasive breast carcinoma. Clin Cancer Res 10: 5367-5374 
Opavsky R, Pastorekova S, Zelnik V, Gibadulinova A, Stanbridge EJ, Zavada J, Kettmann R, Pastorek J (1996) Human MN/CA9 gene, a novel member of the carbonic anhydrase family: structure and exon to protein domain relationships. Genomics 33: $480-487$

Pastorek J, Pastorekova S, Callebaut I, Mornon JP, Zelnik V, Opavsky R, Zat'ovicova M, Liao S, Portetelle D, Stanbridge EJ, Zavada J, Burny A, Kettmann R (1994) Cloning and characterization of MN, a human tumorassociated protein with a domain homologous to carbonic anhydrase and a putative helix-loop-helix DNA binding segment. Oncogene 9: 2877-2888

Perou CM, Sorlie T, Eisen MB, van de Rijn M, Jeffrey SS, Rees CA, Pollack JR, Ross DT, Johnsen H, Akslen LA, Fluge O, Pergamenschikov A, Williams C, Zhu SX, Lonning PE, Borresen-Dale AL, Brown PO, Botstein D (2000) Molecular portraits of human breast tumours. Nature 406: $747-752$

Potter CP, Harris AL (2003) Diagnostic, prognostic and therapeutic implications of carbonic anhydrases in cancer. Br J Cancer 89: 2-7

Rafajova M, Zatovicova M, Kettmann R, Pastorek J, Pastorekova S (2004) Induction by hypoxia combined with low glucose or low bicarbonate and high posttranslational stability upon reoxygenation contribute to carbonic anhydrase IX expression in cancer cells. Int J Oncol 24: 995-1004

Rouzier R, Perou CM, Symmans WF, Ibrahim N, Cristofanilli M, Anderson K, Hess KR, Stec J, Ayers M, Wagner P, Morandi P, Fan C, Rabiul I, Ross JS, Hortobagyi GN, Pusztai L (2005) Breast cancer molecular subtypes respond differently to preoperative chemotherapy. Clin Cancer Res 11: $5678-5685$

Schindl M, Schoppmann SF, Samonigg H, Hausmaninger H, Kwasny W, Gnant M, Jakesz R, Kubista E, Birner P, Oberhuber G (2002) Overexpression of hypoxia-inducible factor lalpha is associated with an unfavorable prognosis in lymph node-positive breast cancer. Clin Cancer Res 8: 1831 - 1837

Semenza GL (2000) Hypoxia, clonal selection, and the role of HIF-1 in tumor progression. Crit Rev Biochem Mol Biol 35: 71-103

Sobhanifar S, Aquino-Parsons C, Stanbridge EJ, Olive P (2005) Reduced expression of hypoxia-inducible factor-1alpha in perinecrotic regions of solid tumors. Cancer Res 65: 7259-7266

Sorlie T, Perou CM, Tibshirani R, Aas T, Geisler S, Johnsen H, Hastie T, Eisen MB, van de Rijn M, Jeffrey SS, Thorsen T, Quist H, Matese JC, Brown PO, Botstein D, Eystein Lonning P, Borresen-Dale AL (2001) Gene expression patterns of breast carcinomas distinguish tumor subclasses with clinical implications. Proc Natl Acad Sci USA 98: 10869-10874

Sorlie T, Tibshirani R, Parker J, Hastie T, Marron JS, Nobel A, Deng S, Johnsen H, Pesich R, Geisler S, Demeter J, Perou CM, Lonning PE, Brown PO, Borresen-Dale AL, Botstein D (2003) Repeated observation of breast tumor subtypes in independent gene expression data sets. Proc Natl Acad Sci USA 100: $8418-8423$

Span PN, Bussink J, Manders P, Beex LV, Sweep CG (2003) Carbonic anhydrase- 9 expression levels and prognosis in human breast cancer: association with treatment outcome. $\mathrm{Br}$ J Cancer 89: 271 - 276

Supuran CT (2008) Development of small molecule carbonic anhydrase IX inhibitors. BJU Int 101(Suppl 4): 39-40

Sutherland RM (1998) Tumor hypoxia and gene expression-implications for malignant progression and therapy. Acta Oncol 37: 567-574

Tan E, Campo L, Han C, Turley H, Pezzella F, Gatter K, Harris A, Fox S (2007) Cytoplasmic location of factor inhibiting-HIF (FIH)-1 is associated with an enhanced hypoxic response and a shorter survival in invasive breast cancer. Breast Cancer Res 9: R89, doi:10.1186/bcr1838

Teicher BA, Holden SA, al-Achi A, Herman TS (1990) Classification of antineoplastic treatments by their differential toxicity toward putative oxygenated and hypoxic tumor subpopulations in vivo in the FSaIIC murine fibrosarcoma. Cancer Res 50: 3339-3344

Teicher BA, Lazo JS, Sartorelli AC (1981) Classification of antineoplastic agents by their selective toxicities toward oxygenated and hypoxic tumor cells. Cancer Res 41: 73-81

Tomes L, Emberley E, Niu Y, Troup S, Pastorek J, Strange K, Harris A, Watson PH (2003) Necrosis and hypoxia in invasive breast carcinoma. Breast Cancer Res Treat 81: 61-69

Tsuda H, Takarabe T, Hasegawa T, Murata T, Hirohashi S (1999) Myoepithelial differentiation in high-grade invasive ductal carcinomas with large central acellular zones. Hum Pathol 30: 1134-1139

Turner KJ, Crew JP, Wykoff CC, Watson PH, Poulsom R, Pastorek J, Ratcliffe PJ, Cranston D, Harris AL (2002) The hypoxia-inducible genes VEGF and CA9 are differentially regulated in superficial $v s$ invasive bladder cancer. Br I Cancer 86: $1276-1282$

van de Rijn M, Perou CM, Tibshirani R, Haas P, Kallioniemi O, Kononen J, Torhorst J, Sauter G, Zuber M, Kochli OR, Mross F, Dieterich H, Seitz R, Ross D, Botstein D, Brown P (2002) Expression of cytokeratins 17 and 5 identifies a group of breast carcinomas with poor clinical outcome. $A m \mathrm{~J}$ Pathol 161: 1991 - 1996

Wetzels RH, Kuijpers HJ, Lane EB, Leigh IM, Troyanovsky SM, Holland R, van Haelst UJ, Ramaekers FC (1991) Basal cell-specific and hyperproliferation-related keratins in human breast cancer. Am J Pathol 138: $751-763$

Wykoff CC, Beasley NJ, Watson PH, Turner KJ, Pastorek J, Sibtain A, Wilson GD, Turley H, Talks KL, Maxwell PH, Pugh CW, Ratcliffe PJ, Harris AL (2000) Hypoxia-inducible expression of tumor-associated carbonic anhydrases. Cancer Res 60: 7075-7083 